Article

\title{
Application of the Artificial Neural Network (ANN) Approach for Prediction of the Kinetic Parameters of Lignocellulosic Fibers
}

\author{
Heitor Luiz Ornaghi, Jr. ${ }^{1, *}$, Roberta Motta Neves ${ }^{2}$ and Francisco M. Monticeli ${ }^{3}$ \\ 1 Department of Materials Engineering, Federal University for Latin American Integration (UNILA), \\ Edifício Comercial Lorivo, Av. Silvio Américo Sasdelli, 1842, Vila A, Foz do Iguaçu 85866-000, PR, Brazil \\ 2 Post-Graduation Program in Mining, Metallurgical and Materials, Federal University of Rio Grande do \\ Sul (UFRGS), Av. Bento Gonçalves, 9500, Setor 4, Prédio 74, Sala 211, Porto Alegre 91501-970, RS, Brazil; \\ roberta.neves@ufrgs.br \\ 3 Departament of Materials and Technology, São Paulo State University (Unesp), School of Engineering, \\ Guaratinguetá 12516-410, SP, Brazil; f.monticeli@unesp.br \\ * Correspondence: hlornagj@ucs.br
}

check for updates

Citation: Ornaghi, H.L., Jr.; Neves, R.M.; Monticeli, F.M. Application of the Artificial Neural Network (ANN) Approach for Prediction of the Kinetic Parameters of Lignocellulosic Fibers. Textiles 2021, 1, 258-267. https:/ / doi.org/10.3390/textiles1020013

Academic Editors: Tao Yang,

Rajesh Mishra, Veerakumar

Arumugam and Noureddine Abidi

Received: 23 May 2021

Accepted: 20 July 2021

Published: 7 August 2021

Publisher's Note: MDPI stays neutral with regard to jurisdictional claims in published maps and institutional affiliations.

Copyright: (c) 2021 by the authors. Licensee MDPI, Basel, Switzerland. This article is an open access article distributed under the terms and conditions of the Creative Commons Attribution (CC BY) license (https:/ / creativecommons.org/licenses/by/ $4.0 /)$.

\begin{abstract}
Lignocellulosic fibers are widely applied as reinforcement in polymer composites due to their properties. The thermal degradation behavior governs the maximum temperature at which the fiber can be applied without significant mass loss. It is possible to determine this temperature using Thermogravimetric Analysis (TG). In particular, when curves are obtained at different heating rates, kinetic parameters can be determined by using Arrhenius-based equations, and more detailed characteristics of the material are obtained. However, every curve obtained at a distinct heating rate demands material, cost and time. Methods to predict thermogravimetric curves can be very useful in the materials science field, and in this sense, mathematical approaches are powerful tools, if well employed. For this reason, in the present study, thermogravimetric curves from curaua fiber were obtained at four different heating rates $\left(5,10,20\right.$ and $\left.40^{\circ} \mathrm{C} \cdot \mathrm{min}^{-1}\right)$ and Vyazovkin kinetic parameters were obtained using free available software. After, the experimental curves were fitted using an artificial neural network (ANN) approach followed by a Surface Response Methodology (SRM) aiming to obtain curves at any heating rate between the minimum and maximum experimental heating rates. Finally, Vyazovkin kinetic parameters were tested again, with the new predicted curves at the heating rates of $7,15,30$ and $50{ }^{\circ} \mathrm{C} \cdot \mathrm{min}^{-1}$. Similar values of the kinetic parameters were obtained compared to the experimental ones. In conclusion, due to the capability to learn from the own data, ANN combined with SRM seems to be an excellent alternative to predict TG curves that do not test experimentally, opening the range of applications.
\end{abstract}

Keywords: lignocellulosic fiber; thermal degradation; kinetic analysis; artificial neural network

\section{Introduction}

Lignocellulosic fibers are versatile materials used in different applications. Their use englobes the entire fiber for reinforcement in composite materials [1,2], or the use of their derivatives (cellulose, hemicellulose or lignin) in particular applications as shape memory of lignin-rubber composites [3], to obtain nanocellulose [4], to reinforce expanded composites [5] or cellulose biomedical applications [6], for example. This wide potential of application can be attributed to the great variety of chemical components (cellulose, hemicellulose, lignin, waxes, low molecular weight components, oil and others) presented in the lignocellulosic fibers $[7,8]$. In addition, the same fiber can have different properties depending on the plant age, climate, soil, among others [9].

Yao et al. [10] studied the thermal degradation behavior of 10 different lignocellulosic fibers, focusing on the Arrhenius kinetic parameters. The activation energy as a function of conversion presented similar values, independently of the chemical content of the fiber 
studied. A linear dependency in the conversion range $\alpha=0.2-0.8$ was observed for all fibers with an average apparent activation energy of $160-170 \mathrm{~kJ} \cdot \mathrm{mol}^{-1}$ for most of the fibers studied. Sunphorka et al. [11] studied an artificial neural network (ANN) model using 150 data from different lignocellulosic fibers in relation to Arrhenius kinetic parameters. The main results indicated that cellulose played a major role in the pre-exponential factor while the hemicellulose on the reaction order. According to the authors, all components affected the activation energy. Ornaghi Jr. et al. [7] studied the kinetic mechanisms involved in the thermal degradation of lignocellulosic fibers based on the chemical composition. The main results indicated that the activation energy of the fibers followed similar values to the cellulose component and that the thermogravimetric curves followed a similar pattern, independently of the chemical composition. Monticeli et al. [12] studied an ANN approach for lignocellulosic fibers using thermogravimetric analysis. The results indicated 50-60 as the optimal number of training datasets for all fibers. In addition, a reliable prediction of TG curves was obtained at different heating rates did not obtain experimentally.

Most of the fibers found in the literature follow a similar curve format, independently of the amount of the chemical components that indicate that the degradation process may follow specific degradation rules. For example, a mass loss of $5-10 \%$ is obtained at $100{ }^{\circ} \mathrm{C}$ due to moisture evaporation and, from $300{ }^{\circ} \mathrm{C}$, the degradation of cellulose occurs. In some cases, a shoulder is observed at DTG (derivative thermogravimetric analysis) due to the higher amount of hemicellulose in a small range before cellulose degradation $[13,14]$. Hence, the thermogravimetric curves prediction of a particular lignocellulosic fiber can be extended to most of the fibers due to these similarities.

The main objective of this study is to perform the thermal degradation kinetic behavior of curaua fiber using the Vyazovkin kinetic method and ANN approach. The experimental curves were kinetically tested and curves that did not test experimentally were predicted, and new kinetic tests were carried out. The results presented reliable and robust data without the necessity of further experimental curves.

\section{Materials and Methods}

Curaua fiber received from CEAPAC (support center for community action projects) was used in this study. More details about the fiber characteristics can be found on [15,16].

Thermogravimetric analysis was carried out in a TA instrument model TGA-50 Shimadzu (Caxias do Sul, Brazil), under nitrogen atmosphere $\left(50 \mathrm{~mL} \cdot \mathrm{min}^{-1}\right)$, from 25 to $900{ }^{\circ} \mathrm{C}$, using $\sim 10 \mathrm{mg}$ of each sample at four distinct heating rates $(5,10,20$ and $40{ }^{\circ} \mathrm{C} \cdot \mathrm{min}^{-1}$ ). The theoretical and predicted curves were used to calculate the kinetic parameters according to the Vyazovkin method. The calculation was carried out using the software developed by Drozin et al. [17]. A previous study Monticeli et al. [12] was used as a base for the obtaining of the new ANN curves at distinct heating rates. The predicted curves were used to calculate the kinetic parameters again and compare the results.

\subsection{Kinetic Approach}

The thermal degradation kinetic of lignocellulosic fibers follows the kinetics of the reaction of solids, in Equation (1):

$$
\frac{d \alpha}{d t}=k(T) f(\alpha)
$$

where $d \alpha / d t$ is the degradation rate, $k(T)$ is the rate constant and $f(\alpha)$ is a conversion function.

The degradation kinetic follows Arrhenius' equation (Equation (2)) and the heating rate changes linearly with temperature (Equation (3)):

$$
\begin{gathered}
k(T)=A e^{-\frac{E a}{R T}} \\
\beta=\frac{d T}{d t}=\text { constant }
\end{gathered}
$$


where $A$ is the pre-exponential factor, $E a$ is the activation energy, $R$ is the gas constant, $T$ is the temperature, $\beta$ is the heating rate and $d T / d t$ is the temperature in function of time.

The reaction model follows Equation (4) that expresses the function $f(\alpha)$ in the Equation (1) in a more analytical form:

$$
f(\alpha)=\alpha^{m}(1-\alpha)^{n}[-\ln (1-\alpha)]^{p}
$$

where $m, n$ and $p$ are constants that represent a number of different reaction models. The characteristic conversion $(\alpha)$ vs. time plot is often reduced to three main types (accelerating, decelerating and sigmoidal). The equation above is a convenient mathematical approximation of the majority of possible mechanisms. For example, if the data obtained present $m$ and $n$ values higher than zero ( 0 ) and not presents a $p$ value, the most probable mechanism is the diffusion one. Different combinations are referred to different mechanisms. More details can be found on [18-21].

In combining Equations (1)-(4) we obtain Equation (5):

$$
\frac{d \alpha}{d T}=\frac{A}{\beta} e^{-\frac{E a}{R T}} \alpha^{m}(1-\alpha)^{n}[-\ln (1-\alpha)]^{p}
$$

The kinetic calculation was performed with the help of the Software developed by Drozin et al. [17] with the experimental and predicted curves.

\subsection{Artificial Neural Network (ANN)}

The ANN is conventionally constructed with three layers, i.e., an input, an output and a hidden layer. Each layer has different numbers of neuronal elements. In the present case, we use as input vectors a set of $i$ TG curves at different heating rates. In this sense, the network will modify the weight of the interconnections between neurons in order to reproduce the given parameters. Figure 1 shows the scheme of the calculation process.

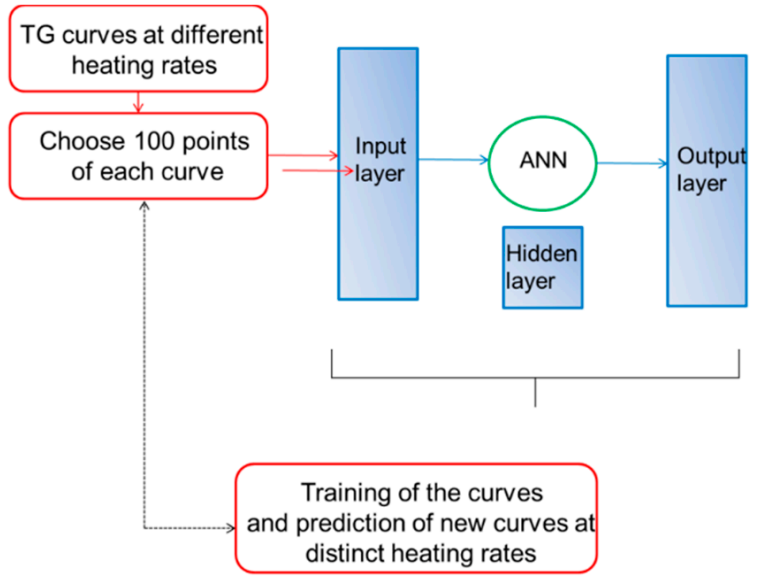

Figure 1. Flowchart of the calculation process.

The main issues necessary to be defined before using the networks are the quality and number of the initial TG curves, the training algorithm and the number of neurons in the hidden layer. The number of initial TG curves used for the training should not be excessively large to avoid the over-training of the network, and it must be distributed correctly, in the sense that it usually appropriate to avoid sets of input vectors with the same output vectors. These kinds of orthogonal combinations produce better results than using random sets of parameters [22]. The following conditions (Table 1) were used to training the ANN network. 
Table 1. Parameters used to perform the ANN fit.

\begin{tabular}{cccccccc}
\hline Technique & $\begin{array}{c}\text { Number } \\
\text { of Layers }\end{array}$ & $\begin{array}{c}\text { Number of } \\
\text { Hidden Neurons } \\
\text { in Each Layer }\end{array}$ & $\begin{array}{c}\text { Training } \\
\text { Repetitions }\end{array}$ & $\begin{array}{c}\text { Neural Network } \\
\text { Algorithm }\end{array}$ & Error Function & $\begin{array}{c}\text { Threshold of } \\
\text { Error Function }\end{array}$ & $\begin{array}{c}\text { Activation } \\
\text { Function }\end{array}$ \\
\hline TGA & 1 & 12 & 3 & $\begin{array}{c}\text { Resilient } \\
\text { backpropagation } \\
\text { with back tracking }\end{array}$ & $\begin{array}{c}\text { Sum of } \\
\text { squared errors }\end{array}$ & $\begin{array}{c}\text { Tangent } \\
\text { hyperbolicus }\end{array}$ \\
\hline
\end{tabular}

With the network training, we can feed the network with different curves and predicted new curves. The main drawback is that the curves outside the lower and higher heating rate cannot be created due to the accumulation of errors [22,23].

\subsection{Surface Response Methodology (SRM)}

The SRM is a statistical approach for modeling and analyzing a process in which the response of interest is affected by various variables [12,24,25]. Equation (6) describes the degradation curve interaction among the combination of temperature and heating rate. In using this method, the statistical relevance is kept and the number of experiments can be reduced.

$$
Z=\gamma_{0}+\sum_{i=1}^{k} \gamma_{i} x_{i}+\sum_{i=1}^{k} \gamma_{i i} x_{i}^{2}+\sum_{j=1}^{k} \gamma_{j} x_{j}+\sum_{j=1}^{k} \gamma_{j j} x_{j}^{2}+\sum_{i=1}^{k-1} \sum_{j=i}^{k} \gamma_{j i} x_{i} x_{j}
$$

where $Z$ represents the predicted response (i.e., degradation curve- $\left.-W_{A N N}(\%)\right), x_{i}$ and $x_{j}$ are variations parameter, in which $i$ represents the $x$-axis (temperature $\mathrm{T}\left({ }^{\circ} \mathrm{C}\right)$ ) and $j$ is the $y$-axis (heating rate $\left.\operatorname{HR}\left({ }^{\circ} \mathrm{C} \cdot \mathrm{min}^{-1}\right)\right) \cdot \gamma_{0}$ is the constant coefficient; $\gamma_{i}$ is the linear coefficient; and $\gamma_{i j}$ is the interaction coefficient.

\section{Results and Discussion}

Figure $2 \mathrm{a}, \mathrm{b}$ showed the experimental thermogravimetric curves and the respective derivatives of curaua fiber at different heating rates. The curves maintained the same format, independently of the heating rate used; only shifting the curve to a higher temperature. Three visible main loss stages are visualized: (i) at around $100{ }^{\circ} \mathrm{C}$, a mass loss of $5 \%$ can be mainly attributed to the evaporation of intrinsic moisture, (ii) at around $300{ }^{\circ} \mathrm{C}$ a more abrupt mass loss attributed mainly to hemicellulose that extends up to $350^{\circ} \mathrm{C}$ and, (iii) from $350{ }^{\circ} \mathrm{C}$ to $400{ }^{\circ} \mathrm{C}$ the degradation of cellulose (the main component) in a narrower range, representing the main degradation stage. Lignin decomposes over different temperature ranges $[7,26,27]$.

All the curves above were used to calculate the kinetic parameters using the Vyazovkin kinetic model in the temperature range from 100 to $435^{\circ} \mathrm{C}$ (main degradation stage). The corrected heating rates (provided by the Software) using the Vyazovkin method were 10.09, 20.1 and $39.79^{\circ} \mathrm{C} \cdot \mathrm{min}^{-1}$. Figure 3 a represents the activation energy in the conversion function and while Figure $3 b$ the degradation rate in the function of conversion degree. An appropriate correlation between the theoretical and calculated degradation rate vs. alpha is obtained. The results presented the following values: $E_{a}=192.02 \mathrm{KJ} \cdot \mathrm{mol}^{-1}, A=10.6 \times 10^{15}$, $m=0.9, n=1.71$ and $p=0$. 

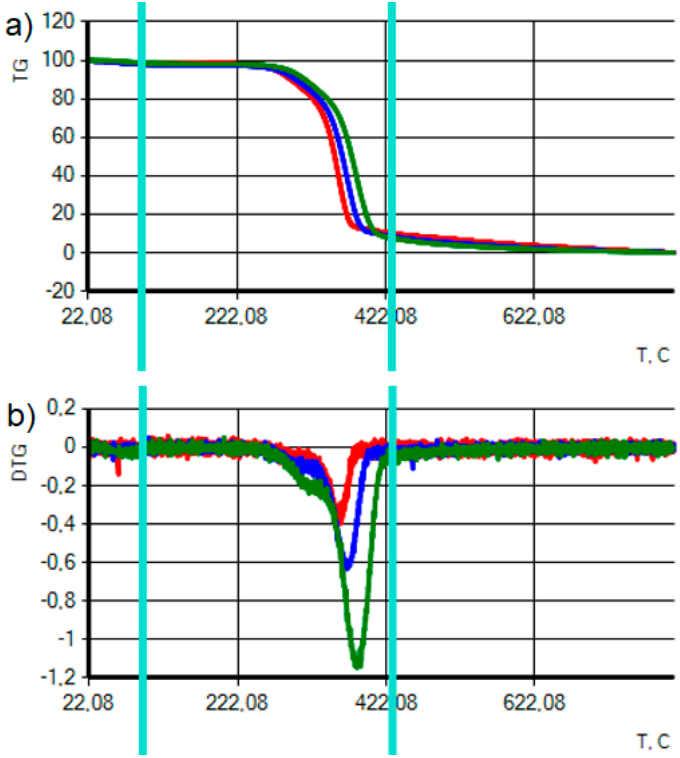

Figure 2. (a) Thermogravimetric and (b) derivative TG curves of curaua fiber at different heating rates. The heating rates of 10,20 and $40{ }^{\circ} \mathrm{C} \cdot \mathrm{min}^{-1}$ are represented by the red, blue and green lines. The vertical cyan lines represent the limit of calculation of the kinetic parameters.

a)

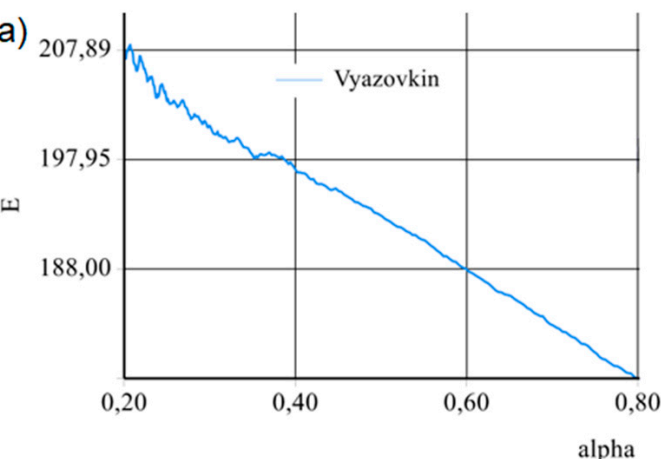

b)

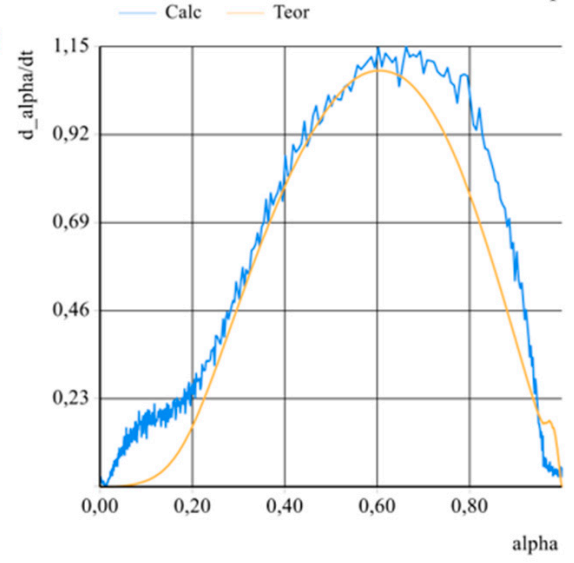

Figure 3. Kinetic calculation of the experimental curves. (a) Activation energy in function of conversion degree and (b) degradation rate in function of conversion degree.

ANN prediction model is detailed in Section 2.2, in which the procedures used to calculate the predicted TGA fit are exhibited in Table 1. Using the same ANN parameters, this analysis can be reproduced for similar TGA curves through several neural network software (e.g., MatLab, OriginLab, CNTK, TFLearn, among others) [28].

Based on experimental degradation curves, the ANN fit was constructed with parameters variation, in which temperature and heating rate as the input parameters and the 
loss of mass (kinetic behavior) as output. The experimental dots were used to training the ANN. The number of training data influences the predictive curve, which was thoroughly investigated in previous work to optimize the ANN method [12]. Figure 4a presents the trained curves with the experimental ones, and Figure $4 \mathrm{~b}$ exhibits the enlargement of initial degradation. An excellent fit was obtained for all heating rates tested. The coefficient of determination was $R^{2}>0.99$ for all curves.
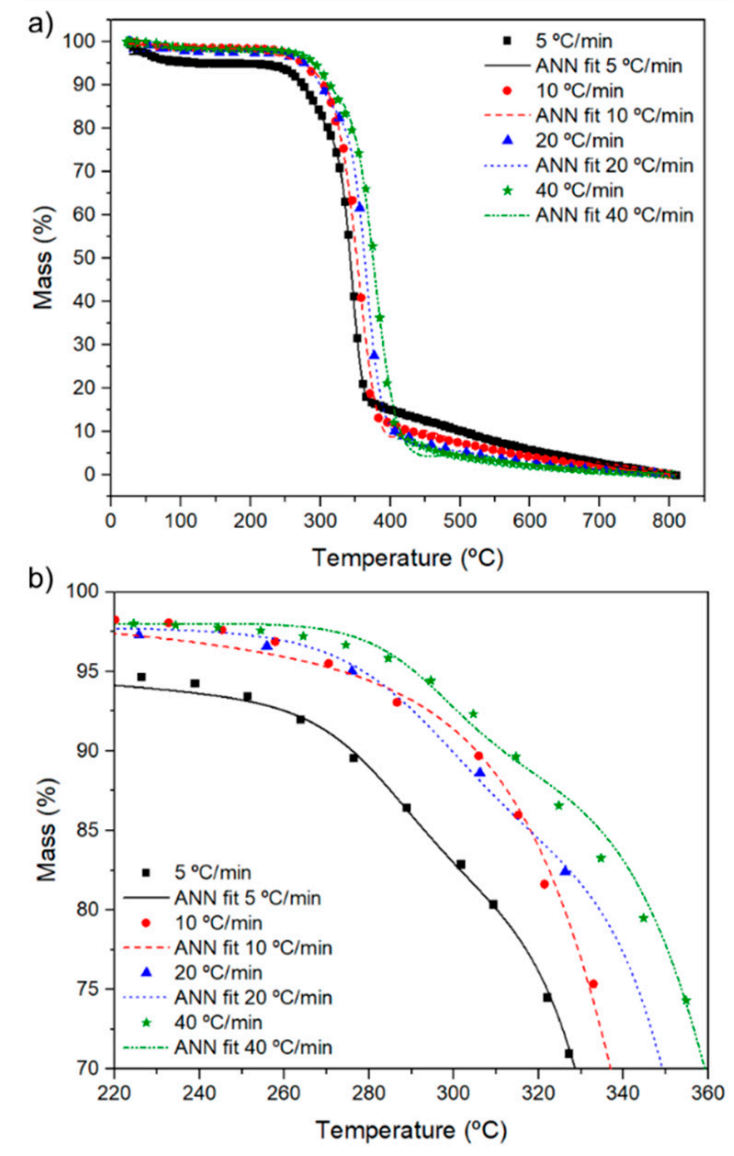

Figure 4. (a) Thermogravimetric curves of curaua fiber at different heating rates trained using ANN approach according to Monticeli et al. [12], and (b) enlargement of initial degradation.

Only 1/10 of the experimental dataset has been used for training the ANN, resulting in a perfect fitting, resulting in an appropriate predictive result. Regarding the ANN application, new degradation behavior could be predicted with no need for long experiments [28].

From the ANN predicted curves, intermediate heating rates were predicted using the surface response methodology (SRM), resulting in a 3D Surface response to predict mass loss as a function of temperature and heating rate variation. Dot curves give the experimental data. The coefficient of determination $R^{2}=0.96$ indicates the high reliability of predicted results. For the lowest heating rate (i.e., $5{ }^{\circ} \mathrm{C} / \mathrm{min}$ ), the degradation curve initiates at the lowest temperature for onset and endset, resulting in the slowest degradation of the remaining residue $(15 \%)$, between $375-810{ }^{\circ} \mathrm{C}$. At higher heating rates, more abrupt degradation occurs, increasing the onset and endset temperatures.

A well-trained ANN could develop a degradation mechanistic understanding of the natural fiber considered, considering that the ANN method is a purely phenomenological approach that can give accurate predictions [29]. For a better approximation of the theoretical and experimental results, the equation of the three-dimensional curve in Figure 5 was divided into three, presented in Equation (7) — for the temperature range of 25-250 ${ }^{\circ} \mathrm{C}$, Equation (8) - for the temperature range of $250-410^{\circ} \mathrm{C}$ and Equation (9) - for the temperature range of $410-810^{\circ} \mathrm{C}$. 


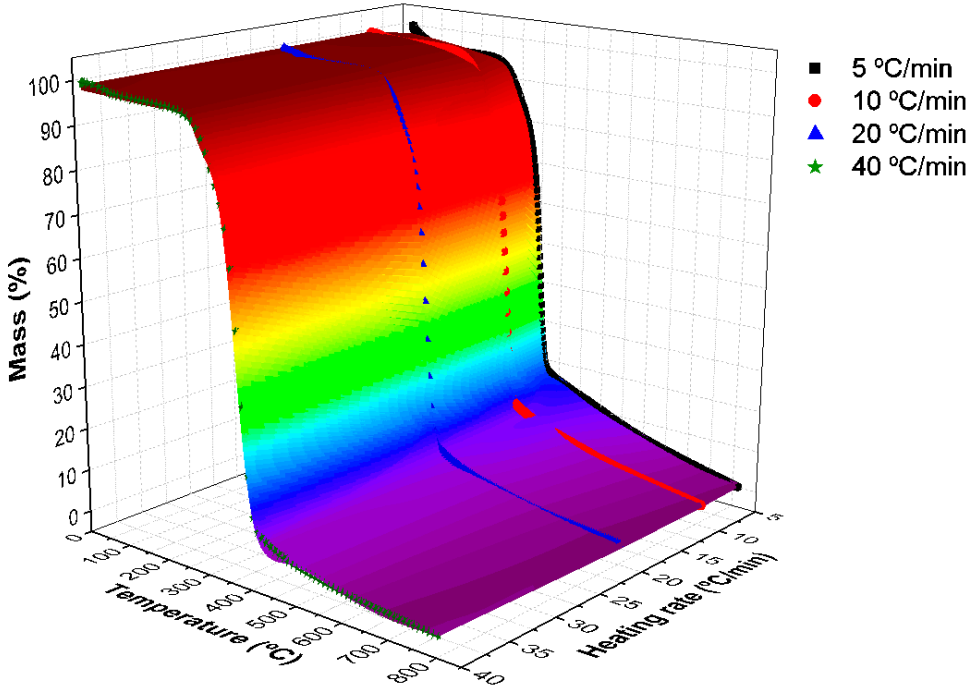

Figure 5. Surface Response Methodology for the thermogravimetric curves.

The SRM curves (Equations (7)-(9)) were generated through a mathematical calculation of a three-dimensional regression plot of the second-order Equation (8). For error reduction and better compatibility with the complex curve presented in this work, the degradation curve was divided into three: room temperature up to $T_{\text {onset }} ; T_{\text {onset }}$ to $T_{\text {endset }} ;$ and $T_{\text {endset }}$ to the final temperature, according to the procedure presented in reference [12].

$$
\begin{gathered}
W_{A N N}=97.5+0.17 \mathrm{HR}-0.007 \mathrm{~T}-0.004 H R^{2}-2.4 \cdot 10^{-5} T^{2}+3.1 \cdot 10^{-4} \mathrm{~T} \cdot \mathrm{HR} \\
W_{\text {ANN }}=-272.7-1.2 \mathrm{HR}+2.83 \mathrm{~T}-0.01 H R^{2}-0.005 \mathrm{~T}^{2}+0.006 \mathrm{~T} \cdot \mathrm{HR} \\
W_{\text {ANN }}=44.4-0.5 \mathrm{HR}-0.09 \mathrm{~T}+0.0054 H R^{2}+4.9 \cdot 10^{-5} T^{2}+3.14 \cdot 10^{-4} \mathrm{~T} \cdot \mathrm{HR}
\end{gathered}
$$

Following SRM results, Figure 6 exhibits the predicted values of the thermogravimetric curves of curaua fiber using the heating rates of $7,15,30$ and $50{ }^{\circ} \mathrm{C} \cdot \mathrm{min}^{-1}$. Through the $\mathrm{ANN}$ and SRM combination, it is possible to predict other degradation curves with different analysis parameters not accessed experimentally, decreasing costs and time related to tests repetitions with high reliability.

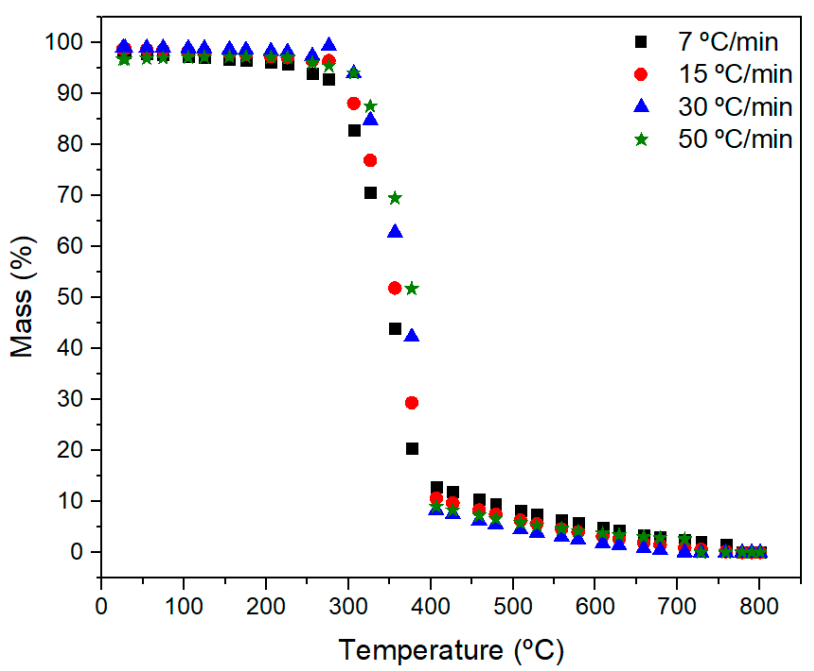

Figure 6. Predicted thermogravimetric curves of curaua fiber.

The new kinetic parameters were caried out using the curves predicted (a) 7, 15 and $30{ }^{\circ} \mathrm{C} \cdot \mathrm{min}^{-1}$ and (b) $7,15,30$ and $50^{\circ} \mathrm{C} \cdot \mathrm{min}^{-1}$. The results presented the following values 
for condition (a): $E_{a}=228.74 \mathrm{KJ} \cdot \mathrm{mol}^{-1}, A=3.59 \times 10^{19}, m=0.1, n=1.00$ and $p=0$ and for condition (b): $E_{a}=226.92 \mathrm{KJ} \cdot \mathrm{mol}^{-1}, A=6.92 \times 10^{18}, m=0.1, n=1.53$ and $p=0$.

The values obtained, mainly the activation energy, are close to the experimental curves. The extrapolated curve $\left(\right.$ at $50^{\circ} \mathrm{C} \cdot \mathrm{min}^{-1}$ ) used in condition b was also obtained. Of course, that the extrapolation of data using ANN is not well recommended due to the accumulation of errors. However, it can be used carefully and seems to work if the behavior did not change drastically from the previous behavior.

To confirm the ANN and SRM predicted methodology through the experimental data, the analysis of variance method was applied to evaluate the statistical influence of the heating rate variation on the $E_{a}$ and $A$ values, as shown in Table 2. The results confirmed that the $E_{a}$ and $A$ are directly proportional to the heating rate fluctuation since in both cases $F>F_{\text {critical }}$ and $p$-value $<0.05$, confirming that there is a significant difference between experimental and predicted values. In addition, the percentage of contribution (PC) shows that error presented less influence on degradation kinetics parameters. This means that even with a slight variation on activation energy and pre-exponential factor, the use of different heating rate values has a high level of contribution in the determination of kinetic degradation parameters.

Table 2. Analysis of variance results.

\begin{tabular}{ccccc}
\hline & $\boldsymbol{F}$ & $\boldsymbol{p}$-Value & $\boldsymbol{F}_{\text {critical }}$ & $\boldsymbol{P C} \mathbf{( \% )}$ \\
\hline$E_{a}$ & 255.88 & $8.93 \times 10^{-5}$ & 7.71 & 99.80 \\
error & & & & 0.20 \\
\hline$A$ & 16.64 & 0.015 & 5.14 & 94.15 \\
error & - & - & - & 5.85 \\
\hline
\end{tabular}

As a matter of fact, the $t$-test exhibits a $p$-value $=0.10$, which is higher than 0.05 . This result indicated that the experimental value presents no significative divergency than predicted values (true null hypothesis).

\section{Conclusions}

The present study proposed obtaining new thermogravimetric curves for curaua fiber at any heating rate between the minimum and maximum heating rates experimentally tested. For this, an Artificial Neural Network (ANN) followed by the Surface Response Methodology (SRM) was used to obtain new TG curves. Vyazovkin kinetic method was used in the experimental curves and in the newly obtained curves. The kinetic results presented similar values for the experimental and predicted curves, confirmed by statistical analysis. This approach can be extended to any material to obtain properties, parameters or to optimize processes.

Author Contributions: Conceptualization, H.L.O.J.; formal analysis, H.L.O.J.; investigation, H.L.O.J., F.M.M. and R.M.N.; methodology: H.L.O.J., F.M.M. and R.M.N.; Supervision, H.L.O.J; writingoriginal draft, H.L.O.J.; writing — review and editing: F.M.M. and R.M.N. All authors have read and agreed to the published version of the manuscript.

Funding: This research received no external funding.

Institutional Review Board Statement: Not applicable.

Informed Consent Statement: Not applicable.

Data Availability Statement: Not applicable.

Conflicts of Interest: The authors declare no conflict of interest. 


\section{References}

1. Angrizani, C.C.; Ornaghi, H.L., Jr.; Zattera, A.J.; Amico, S.C. Thermal and Mechanical Investigation of Interlaminate Glass/Curaua Hybrid Polymer Composites. J. Nat. Fibers 2017, 14, 271-277. [CrossRef]

2. Silva, H.S.P.; Ornaghi, H.L., Jr.; Almeida, J.H.S., Jr.; Zattera, A.J.; Amico, S.C. Mechanical Behavior and Correlation between Dynamic Fragility and Dynamic Mechanical Properties of Curaua Fiber Composites. Polym. Compos. 2014, 35, $1078-1086$. [CrossRef]

3. Nguyen, N.A.; Meek, K.M.; Bowland, C.C.; Naskar, A.K. Data of thermally active lignin-linkages and shape memory of lignin-rubber composites. Data Br. 2019, 22, 392-399. [CrossRef]

4. Neves, R.M.; Lopes, K.S.; Zimmermann, M.G.V.; Poletto, M.; Zattera, A.J. Cellulose Nanowhiskers Extracted from TempoOxidized Curaua Fibers. J. Nat. Fibers 2019, 17, 1355-1365. [CrossRef]

5. Neves, R.M.; Lopes, K.S.; Lazzari, L.K.; Monticeli, F.M.; Zattera, A.J. Characterization of expanded polystyrene and its composites by supercritical carbon dioxide foaming approach. J. Porous. Mater. 2021. [CrossRef]

6. Seddiqi, H.; Oliaei, E.; Honarkar, H.; Jin, J.; Geonzon, L.C.; Bacabac, R.G.; Nulend, J.K. Cellulose and its derivatives: Towards biomedical applications. Cellulose 2021, 28, 1893-1931. [CrossRef]

7. Ornaghi, H.L., Jr.; Ornaghi, F.G.; Neves, R.M.; Monticeli, F.M.; Bianchi, O. Mechanisms involved in thermal degradation of lignocellulosic fibers: A survey based on chemical composition. Cellulose 2020, 4949-4961. [CrossRef]

8. Yang, J.; Ching, Y.C.; Chuah, C.H. Applications of lignocellulosic fibers and lignin in bioplastics: A review. Polymers 2019, $11,751$. [CrossRef]

9. Abdul, H.P.S.A.; Hossain, M.S.; Rosamah, E.; Azli, N.A.; Saddon, N.; Davoudpoura, Y.; Islam, N.; Dungani, R. The role of soil properties and it's interaction towards quality plant fiber: A review. Renew. Sustain. Energy Rev. 2015, 43, 1006-1015. [CrossRef]

10. Yao, F.; Wu, Q.; Lei, Y.; Guo, W.; Xu, Y. Thermal decomposition kinetics of natural fibers: Activation energy with dynamic thermogravimetric analysis. Polym. Degrad. Stab. 2008, 93, 90-98. [CrossRef]

11. Sunphorka, S.; Chalermsinsuwan, B.; Piumsomboon, P. Artificial neural network model for the prediction of kinetic parameters of biomass pyrolysis from its constituents. Fuel 2017, 193, 142-158. [CrossRef]

12. Monticeli, F.M.; Neves, R.M.; Ornaghi, H.L., Jr. Using an artificial neural network (ANN) for prediction of thermal degradation from kinetics parameters of vegetable fibers. Cellulose 2021, 28, 1961-1971. [CrossRef]

13. Asim, M.; Paridah, M.T.; Chandrasekar, M.; Shahroze, R.M.; Jawaid, M.; Nasir, M.; Siekeng, R. Thermal stability of natural fibers and their polymer composites. Iran. Polym. J. 2020, 29, 625-648. [CrossRef]

14. Monteiro, S.N.; Calado, V.; Margem, F.M.; Rodriguez, R.J.S. Thermogravimetric stability behavior of less common lignocellulosic fibers-A review. J. Mater. Res. Technol. 2012, 1, 189-199. [CrossRef]

15. Ornaghi, H.L., Jr.; Zattera, A.J.; Amico, S.C. Thermal behavior and the compensation effect of vegetal fibers. Cellulose 2014, 21, 189-201. [CrossRef]

16. Neves, R.M.; Lopes, K.S.; Zimmermann, M.G.V.; Poletto, M.; Zattera, A.J. Characterization of polystyrene nanocomposites and expanded nanocomposites reinforced with cellulose nanofibers and nanocrystals. Cellulose 2019, 26, 4417-4429. [CrossRef]

17. Drozin, D.; Sozykin, S.; Ivanova, N.; Olenchikova, T.; Krupnova, T.; Krupina, N.; Avdin, V. Kinetic calculation: Software tool for determining the kinetic parameters of the thermal decomposition process using the Vyazovkin Method. SoftwareX 2020, 11, 100359. [CrossRef]

18. Vyazovkin, S.; Burnham, A.K.; Criado, J.M.; Pérez-Maqueda, L.A.; Popescu, C.; Sbirrazzuoli, N. ICTAC Kinetics Committee recommendations for collecting experimental thermal analysis data for kinetic computations. Thermochim. Acta. 2011, 590, 1-23. [CrossRef]

19. Šesták, J.; Berggren, G. Study of the kinetics of the mechanism of solid-state reactions at increasing temperatures. Thermochim. Acta 1971, 3, 1-12. [CrossRef]

20. Vyazovkin, S.V.; Lesnikovich, A.I. Practical application of isoconversional methods. Thermochim. Acta 1992, $203,177-185$. [CrossRef]

21. Vyazovkin, S. Evaluation of activation energy of thermally stimulated solid-state reactions under arbitrary variation of temperature. J. Comput. Chem. 1997, 18, 393-402. [CrossRef]

22. Schmidhuber, J. Deep Learning in neural networks: An overview. Neural. Netw. 2015, 61, 85-117. [CrossRef]

23. Agnol, L.D.; Ornaghi, H.L., Jr.; Monticeli, M.F.; Dias, F.T.G.; Bianchi, O. Polyurethanes synthetized with polyols of distinct molar masses: Use of the artificial neural network for prediction of degree of polymerization. Polym. Eng. Sci. 2021, 61, 1810-1818. [CrossRef]

24. Debnath, S.; Reddy, M.M.; Yi, Q.S. Influence of cutting fluid conditions and cutting parameters on surface roughness and tool wear in turning process using Taguchi method. Meas. J. Int. Meas. Confed. 2016, 78, 111-119. [CrossRef]

25. Aydar, A.Y. Utilization of Response Surface Methodology in Optimization of Extraction of Plant Materials. Stat. Approaches Emphas. Des. Exp. Appl. Chem. Process. 2018. [CrossRef]

26. Patwardhan, P.R.; Brown, R.C.; Shanks, B.H. Understanding the fast pyrolysis of lignin. ChemSusChem 2011, 4, 1629-1636. [CrossRef] [PubMed]

27. Cabeza, A.; Sobrón, F.; Yedro, F.M.; García-Serna, J. Autocatalytic kinetic model for thermogravimetric analysis and composition estimation of biomass and polymeric fractions. Fuel 2015, 148, 212-225. [CrossRef] 
28. Fernández-Fdz, D.; López-Puente, J.; Zaera, R. Prediction of the behaviour of CFRPs against high-velocity impact of solids employing an artificial neural network methodology. Compos. Part A Appl. Sci. Manuf. 2008, 39, 989-996. [CrossRef]

29. Muravyev, N.V.; Luciano, G.; Ornaghi, H.L., Jr.; Svoboda, R.; Vyazovkin, S. Artificial Neural Networks for Pyrolysis, Thermal Analysis, and Thermokinetic Studies:The Status Quo. Molecules 2021, 26, 3727. [CrossRef] [PubMed] 